\title{
Utopia e sociabilidade: imagens de sofrimento e caridade no Juazeiro do $\mathrm{N}$ orte ${ }^{1}$
}

\author{
Roberta Bivar C. Campos \\ Professora adjunta do Programa de Pós-graduação \\ em A ntropologia - UFPE
}

\begin{abstract}
RESUMO : Neste artigo, ofereço uma discussão de como imagens de sofrimento e caridade estão relacionadas com imagens de uma sociedade ideal numa comunidade de penitentes do Juazeiro do Norte: os "Ave de Jesus". A través dos significados de sofrimento, pobreza e mendicância, estarei explorando a maneira como os Ave de Jesus criam uma sociabilidade baseada na generosidade, na hospitalidade e no compartilhamento, por meio da qual realizam uma espera messiânica. A análise dos dados etnográficos insere-se na discussão clássica sobre as bases da vida social, tomando-se criticamente a literatura antropológica tradicional sobre dádiva e reciprocidade.
\end{abstract}

PALAVRAS-CHAVE: dádiva; sentimentos morais; espera messiânica.

\section{Introdução}

Antes de iniciar a discussão propriamente dita deste artigo, faço algumas observações quanto ao objeto etnográfico que é a fonte de reflexão do problema a ser aqui desenvolvido: os Ave de Jesus e a produção de uma sociabilidade fundada em sentimentos morais. O s Ave de Jesus são 
uma comunidade de penitentes do Juazeiro do Norte (CE) que vive sob 0 voto da pobreza e castidade, e que tem na mendicância a base de sua subsistência e de sua existência social e moral. A comunidade Ave de Jesus, na época de meu trabalho de campo, tinha em torno de 24 membros. Mas o número vem caindo ao longo dos anos devido tanto ao forte ascetismo, que interdita a seus membros a prática sexual, como à grande evasão de jovens. Segundo informação de um dos integrantes, os Ave de Jesus já chegaram a ter 60 pessoas.

No Juazeiro, há uma grande variedade de formas de penitência. Ora essas penitências constituem uma atividade ritualística coletiva, ora se restringem a práticas individuais. Os Ave de Jesus chamam a atenção por ser o único grupo de penitentes, atualmente, no Juazeiro, no qual seus membros estão organizados em uma comunidade, compartilhando não apenas ritos e crenças, mas uma organização social própria.

Essa comunidade acredita viver em tempos bíblicos, sendo os eventos da Bíblia parte de sua própria história. Em outras palavras, os eventos e personagens bíblicos aconteceram e viveram nas redondezas do Juazeiro do Norte. Estarei aqui reconhecendo a existência, no Sertão, de uma "cultura bíblica" (Velho, 1995)² que funciona como referência para o pensamento e ação; ou seja, a constituição de um modo de vida, de uma sociabilidade. Imagens da Paixão de Cristo são talvez as principais representações que compõem a cultura bíblica entre os Ave de Jesus. Essas imagens evocam sentimentos morais, como sofrimento, compaixão e amor. Entendo, assim, a cultura desse grupo como uma forma de discurso expressa num complexo de narrativas (Bíblia, "causos" e benditos) que envolvem uma moralidade particular e relações sociais também bastante particulares (Macintyre, 1981). Ressalto a importância dos sentimentos morais criados e reproduzidos através das imagens bíblicas presentes nos "causos" contados, nas passagens bíblicas lembradas e cantadas nos benditos. Esses sentimentos tomam lugar especial dentro de 
uma sociabilidade baseada na caridade. Reconheço, assim, a importância do papel dos sentimentos para se compreender a ideologia e 0 comportamento social (D elumeau, 1967 apud Baêta Neves, 1997).

D iscutirei ao longo das próximas páginas a questão de uma sociabilidade que contrasta com aquela fundada na reciprocidade, entendida aqui como "troca". Não estou negando a importância da reciprocidade no desenvolvimento teórico da Antropologia ou na constituição do social. Entretanto, desde a teoria da reciprocidade elaborada por LéviStrauss, como G odelier (1999) salienta, a teoria da dádiva enfatiza a troca e uma outra dimensão da vida social tem sido, se não negligenciada, certamente mal formulada pelas Ciências Sociais (Godbout, 1999; G odelier, 1999, 2001). Não tenho a pretensão de resolver essa deficiência da disciplina, mas, quem sabe, ampliar a discussão na medida em que organizo as inquietações teóricas geradas por minha experiência de campo, com os Ave de Jesus, no qual a especificidade local escapa a explicações universalizantes.

A deficiência teórica em tratar a dádiva, apontada acima, certamente deve-se ao caráter próprio do fenômeno que apresenta uma dimensão mais próxima sobretudo do lado dialético - já sugerido em Mauss -, no qual interesse e desinteresse, obrigação e espontaneidade se confundem mais do que se separam, mas que têm sido, entretanto, reduzidos à troca. Certamente na obra de Lévi-Strauss encontramos passagens em que ele reconhece o lado ambíguo da dádiva, realizando no nível descritivo observações de como interesse e desinteresse, obrigação e espontaneidade, razão e sentimento se misturam neste fenômeno. Lévi-Strauss, de fato, mostrou que, talvez, o principal papel da dádiva esteja na capacidade que tem de criar laços sociais - laços de aliança e amizade, evitando-se a guerra, a hostilidade e o medo (Lévi-Strauss, 1982, p. 107). 0 autor mostra assim que a dádiva gera sentimentos e forja sociabilidade particular de acordo com tais sentimentos. Nas palavras do próprio Lévi-Strauss: 
E da luta passa-se com efeito imediatamente aos presentes, presentes recebidos, presentes dados, mas silenciosamente, sem regateio, sem expressão de satisfação e sem reclamação, e sem ligação aparente entre o que é oferecido e o que é obtido. Trata-se, portanto, realmente de dons recíprocos e não de operações comerciais. Mas pode ser atingido um estágio suplementar: dois bandos que chegaram assim a estabelecer relações cordiais duráveis podem decidir, de maneira deliberada, fundirem-se, instaurando entre os membros masculinos dos dois bandos respectivos uma relação artificial de parentesco, a de cunhados. $\mathrm{Ou}$, levando-se em conta o sistema matrimonial Nhambkwara, esta inovação tem por conseqüência imediata que todas as crianças de um grupo tornam-se cônjuges potenciais das crianças do outro grupo, e reciprocamente. Existe uma transição contínua da guerra às trocas e das trocas aos intercasamentos. E a troca das noivas é apenas o termo de um processo ininterrupto de dons recíprocos, que realiza a passagem da hostilidade à aliança, da angústia à confiança, do medo à amizade. (1982, p. 107, grifo meu)

Entretanto, Lévi-Strauss peca em sua síntese teórica. ${ }^{3} \mathrm{~A}$ reciprocidade em sua obra acaba por ganhar em última instância um caráter cognitivo e simbólico. A troca é reduzida a uma estrutura cognitiva universal fundada na reciprocidade. É na proibição do incesto e na troca das mulheres que 0 autor encontra o fundamento do social, a reciprocidade. Neste sentido, ele se distancia das discussões e questões da sociabilidade e volta-se à lógica das estruturas mentais inconscientes (ver capítulos I , II e XXIX, Natureza e cultura, O problema do incesto e O s princípios do parentesco, no livro E struturas E lementares do Parenteso).

A ênfase estruturalista em funções e aspectos cognitivos das formas culturais em detrimento de suas funções sociais e práticas é assim colocada por Bourdieu: 
Revista de Antropologia, São Paulo, USP, 2003, v. 46 № 1.

pelo fato de construir-se do ponto de vista estritamente intelectualista que é o da decifragem, a lingüística saussuriana privilegia a estrutura dos signos, isto é, as relações que eles mantêm entre si, em detrimento de suas funções práticas que não se reduzem jamais, como supõe tacitamente 0 estruturalismo, às funções de comunicação ou de conhecimento. As práticas mais estritamente voltadas, na aparência, para as funções de comunicação (função fática) ou de comunicação para o conhecimento, como as festas e as cerimônias, as trocas rituais ou, num outro campo, a circulação de informação científica, estão sempre orientadas também para as funções políticas e econômicas. (1983, p. 52)

Tal ênfase estruturalista liga-se a um objetivismo, ainda segundo Bourdieu, que o estruturalismo não consegue superar; posto a estrutura ou o modelo (as relações entre os signos), acaba por se tornar uma realidade autônoma, dotada de eficácia social e capaz de agir enquanto sujeito responsável por ações históricas e produzir práticas (idem, p. 56). Lévi-Strauss passa assim muito facilmente do "modelo da realidade para a realidade do modelo" (idem, p. 59).

Essa crítica a Lévi-Strauss pode ser encontrada em Godbout (1999) e em Godelier (2001). Godbout (1999, p. 147-48) assim diz "o que incomoda, entretanto, na leitura estruturalista é o uso que ela faz do conceito de troca, no qual ela fundamenta sua dimensão abstrata e quase esotérica" . A crítica mais contundente ao modelo racionalista, abstrato e matemático do estruturalismo encontra-se, no entanto, em um artigo de 1951, de Claude Lefort, quando o estruturalismo estava no ápice:

por sistema ele entende função matemática. Apenas esquece que o sistema só é obtido pelo preço da negação do social. As matemáticas, certamente, podem permitir dar uma representação exata de fenômenos sociais, mas esta exatidão é tão pouco a realidade que não a adquiro a não ser por uma 
redução: ponho um conjunto de sinais comparáveis e transponíveis no lugar do mundo de sujeitos constituindo-se mutuamente como objetos-sujeitos. Não devo, pois, perder nunca de vista que a matematização que opero visa somente a uma expressão parcial da realidade e permanece necessariamente subordinada a uma compreensão totalizante. (...)

Em suma, o que censuraríamos em Lévi-Strauss é de apreender na sociedade "regras" ao invés de "comportamentos", retomando expressões de Mauss; e de dá a si artificialmente uma racionalidade total a partir da qual os grupos e os homens são reduzidos a uma função abstrata ao invés de fundá-la sobre as relações concretas que venham a travar entre si. (1979, p. 28-29)

O que Lefort nos oferece como saída é o deslocamento das funções cognitivas para as funções práticas (social). A dádiva seria a própria possibilidade da constituição do humano, a base sobre a qual toda ordem cultural se realiza: o político, o econômico, o social e a moral. Enfim, a lógica do dom não se encontraria nas motivações individuais, mas no cogito coletivo. Nas palavras de Lefort, "Não se dá para receber; dá-se para que o outro dê" (idem, p. 33); nesse sentido, a recusa ao dom seria uma ameaça à sociedade. "Não se pode ser tolerado que o dom não seja restituído não somente porque um indivíduo se sente insultado a título privado, em virtude desta recusa de comunicação, mas porque através dela é a sociedade que se acha ameaçada ou, melhor dizendo, a própria realidade humana" (idem, p. 34).

A beleza e 0 brilhantismo do pensamento de Lefort é inegável e sem dúvida um avanço. Entretanto, apesar da forte crítica a Lévi-Strauss e da defesa de Marcel Mauss pelo seu esforço em compreender a intenção imanente às condutas e portanto à valorização do plano vivido, Lefort não escapa, ele mesmo, ao racionalismo e à idéia da reciprocidade como forma universal de contrato social. 
Revista de Antropologia, São Paulo, USP, 2003, v. 46 № 1.

Já G odbout avança sobre a insuficiência da teoria estruturalista quanto ao problema espeáfico da dádiva, não tratado por Bourdieu ou Lefort:

Lévi-Strauss impede que se compreenda o essencial, ou seja, as razões do extraordinário encarniçamento com que as sociedades primitivas resistiram a todas as tentativas de transformar as dádivas em mercadorias. ${ }^{4}$ Em suma, a noção de intercâmbio não parece suscetível de ser assim universalizada, e o simples fato de falar de troca faz imediatamente e inapelavelmente com que se recaia no âmbito de uma interpretação econômica da dádiva. M. Mauss tem portanto razão de desconfiar dela e de falar daquilo "que é tão mal denominado troca", o "escambo", pois justamente o que falta entender, a não ser recaindo no economicismo que o estruturalismo pretendia superar, são as razões pelas quais, pelo menos nos neyócios importantes, os homens das sociedades primitivas não trocam, mas dão. (1999, grifo meu)

Assim como Godbout, outros autores debruçam-se sobre o problema da dádiva e apontam para a incapacidade de diversas formulações teóricas em trabalhar o que este fenômeno tem de específico (G odbout e Caillé, 1999; G odelier,1999; Testart, 1998; Silber, 1998; Overing, 1992, 1999). Ou em outros termos, de questionarmos a reciprocidade como fundamento universal da vida social ou como uma forma universal de contrato social. ${ }^{5} \mathrm{G}$ odbout, por exemplo, apesar da superficialidade com que elabora um panorama de várias abordagens e autores, tais como, Malinowski, Polanyi, Steward, Marvin Harris, Lévi-Strauss, Girard, Weiner e outros, observa um ponto importante: nessas interpretações a dádiva é sempre explicada por algo que lhe é externo, que, em geral, é algum universal (razão, proibição do incesto etc.) (G odbout, 1999). O bserva ainda que apesar de alguns autores reconhecerem a ambiguiidade da reciprocidade (interesse e desinteresse; cálculo instrumental e razão simbólica), eles mesmos falham, pois a explicação da 
dádiva que formulam é, em última instância, fornecida pela troca seja esta consciente ou inconsciente, material ou simbólica. Disso decorre que não há, nessas formulações teóricas, distinção entre os dois fenômenos, permanecendo, então, o mistério do por que povos que apresentam formas de troca mercantil pura também troquem através da dádiva (1999). Por que a troca de que ser disfarçada por dons? O u ainda, será que a dádiva pura não existe? Não existe solidariedade motivada por valores morais, só aquela por cálculo? O s seres humanos são em última instância máquinas calculadoras? Como Elster (1994) bem coloca, se reduzimos tudo a interesses, somos obrigados a negar a existência do altruísmo.

A problematização de que algumas sociedades entendam a reciprocidade (troca) como anti-social e busquem ou, até mesmo, formulem teorias sociais sobre suas relações sociais como fundadas em princípios morais, ainda são merecedoras de atenção sócio-antropológica. ${ }^{6} \mathrm{~A}$ credito que com o problema da caridade justifica-se 0 questionamento do papel de certas noções e sentimentos morais tais como generosidade e solidariedade - enquanto opostos à rivalidade e à troca - na constituição da sociabilidade. Nesse sentido, divido com alguns autores, G odelier (1999), G odbout (1992), Parry (1998; 1986) e Overing (1992, 1999), a inquietação sobre outras bases para as relações sociais, sejam estas ao lado ou para além da troca. Apesar desses autores situarem-se em linhas de pensamento distintas, eles têm em comum a preocupação em introduzir em suas formulações o problema da moralidade na fabricação do social. Sigo de modo mais próximo Joanna $O$ vering quanto à análise do social, em um nível sobretudo micro das negociações individuais, a importância da vida cotidiana e de como as relações sociais são aí formuladas. O vering também recupera para o debate o compartilhamento, e não a troca, como uma possibilidade de fundamento da vida social. Tomo também G odelier no reconhecimento dos sentimentos na cons- 
Revista de Antropologia, São Paulo, USP, 2003, v. 46 № 1.

tituição do social e de se trabalhar no nível mais imaginário que simbólico, para se compreender a fabricação do social. Como o próprio Godelier explica:

Não se trata de negar a existência das três funções (o imaginário, o simbólico, e o "real") dessas três ordens que se combinam para compor a existência social dos humanos, sua realidade social. 0 problema é saber se é possível construir representações mais adequadas a esta realidade afirmando que o simbólico domina o imaginário ou supondo o inverso. A nossos olhos, esta perspectiva inversa é a que se deve adotar. São antes de tudo as diversas maneiras como os homens imaginam suas relações entre eles com aquilo que chamamos de natureza que distinguem as sociedades, assim como as épocas durante as quais algumas delas continuam a existir. Mas o imaginário não pode se transformar em social, fabricar "sociedade", existindo apenas idealmente. Precisa materializar-se em relacoóes concretas que tomam forma e conteúdo nas instituiọeses e, claro, nos símbolos que as representam e fazem com que correspondam entre si, que se comuniquem. "Materializando-se" em relações sociais, o imaginário torna-se parte da realidade social. (2001, p. 46)

G odelier ainda, acertadamente, aponta para o fato de que a troca faz parte da vida social, mas a vida social não é somente uma questão de reciprocidade. Há, segundo este autor, nas esquinas da rede de relações sociais, valores que não são conectados à negociabilidade da reciprocidade (idem, p. 203-7). Godelier salienta ainda que as análises do que não é negociável

colocam em questão um postulado, piedosamente recebido e unanimemente respeitado, celebrado sobretudo depois da introdução de LéviStrauss à obra de Mauss, a saber, que tudo é troca no ser do homem e que 
é partindo da necessidade da troca que se compreende o funcionamento das sociedades. (idem, p. 166)

Meu argumento encontra ressonância nos de Overing, Godelier, Silber e Parry no sentido de se contrapor à racionalidade instrumental como o modelo únio para a explicação da vida social. Acredito, assim, que a questão da caridade, generosidade e fraternidade pode ser um bom caminho para se discutir outros elementos, além da troca e racionalidade instrumental, que pertencem ao domínio da sociabilidade, como as emoções, os sentimentos e a moral.

A questão central deste artigo não está tanto no reconhecimento ou não, entre os autores, da ambigüidade das trocas recíprocas (o interesse e o desinteresse), mas no postulado da reciprocidade como fundamento universal da vida social. De modo que a especificidade do fenômeno da dádiva se perde em favor de trocas, ainda que recíprocas. A dádiva, na realidade, torna-se uma troca disfarçada simplesmente. Meu esforço, neste artigo, é justamente apontar para as implicações da prática da caridade, entre os Ave de Jesus, na criação de uma sociabilidade na qual reciprocidade surge sob o signo da solidariedade mais do que da troca (cálculo).

\section{Pobreza, caridade e sentimentos morais no Juazeiro do N orte}

Pobreza voluntária e mendicância são imagens tradicionalmente centrais ao sistema religioso do catolicismo do Sertão.?

"O homem não pode ser escravo do homem" - diria freqüentemente Padre Ibiapina, e, mais tarde, Antonio Conselheiro o repetiria $(\mathrm{Cu}-$ nha, 1979; Anderson, 1970). Tanto um como outro vagaram pelo sertão mendigando e pregando a Bíblia. Acusados de tramar contra a ordem 
social, eles apenas acreditavam estar pregando as palavras do Cristo. Inspirados pelas imagens do cristianismo primitivo, pensavam poder recriar, em suas próprias vidas e nas dos sertanejos que os seguiam, os tempos bíblicos. E, assim, trouxeram junto com suas pregações noções de fraternidade, generosidade, misericórdia e caridade que, por sua vez, tiveram implicações sociais e políticas para aqueles que os seguiram e para a sociedade como um todo.

Uma sociedade baseada num sistema socioeconômico, que exclui mais do que promove comunhão, não poderia deixar de ser rejeitada por esses líderes religiosos. A moralidade que funda o pensamento de Padre Ibiapina e Antonio Conselheiro encontra suas raízes numa antiga tradição do pensamento ocidental que vem desde Aristóteles, passa por Tomás de Aquino e chega a Karl Marx. Esses pensadores têm em comum a valorização dos laços comunais e da produção para o uso em detrimento da troca orientada para o lucro e dos valores individuais, que são entendidos como destruidores da vida em comunidade (Bloch e Parry, 1982, p. 2).

Essa visão parece também estar presente no campesinato de modo mais geral (Taussig, 1980) e em algumas comunidades messiânicas do Sertão como Canudos e Caldeirão (Anderson, 1970; D ella Cava, 1970). Meus dados também revelaram a presença dessa moralidade em grupos de penitentes do Juazeiro do Norte (Ave de Jesus, Irmandade da Cruz, D ança de São Gonçalo) onde lucro, interesse individualista, relações impessoais e luxo são contrastados com a valorização moral da prática da pobreza, simplicidade e fortalecimento dos laços comunais que garantem a solidariedade social local (Campos, 2001).

D e fato, a Bíblia foi para Padre Ibiapina, Antonio Conselheiro e Padre Cícero, e continua sendo para muitos sertanejos, uma referência de sociabilidade. 0 Antigo Testamento conta a essa gente histórias de como um povo, que vivia em uma área desértica, enfrentava suas dificuldades. 
Uma das mensagens mais salientes que se encontra na Bíblia é passada através de histórias sobre hospitalidade, compartilhamento e mutualidade num ambiente hostil. D a mesma forma, os sertanejos também vivem em um ambiente adverso, enfrentando longos períodos de estiagem e o flagelo da escassez e da fome. A Bíblia é para essa gente, no meu entender, mais do que um caminho de salvação. É um modelo, um modo de vida. Por outro lado, é importante observar a grande capacidade do sertanejo em se organizar de forma produtiva e eficiente baseado em sentimentos morais como generosidade, fraternidade, hospitalidade, que são referências para a criação de sua sociabilidade. ${ }^{8}$

Mais do que algo simplesmente restrito ao sistema religioso, chamo atenção aqui para 0 fato de como a "mendicância" se mistura a algo mais amplo, que é a cultura local expressa nos folguedos. Maria Isaura Pereira de Q ueiroz descreve em obra clássica da antropologia brasileira, $\mathrm{C}$ ampesinato brasileiro, como a solidariedade das famílias campesinas realizase através de sua religiosidade expressa nos folguedos em que há presença marcante da esmola. A folia sairia "de sítio em sítio, tocando, cantando e pedindo esmolas" (Queiroz, 1973). Certamente esse ritual é parte do calendário religioso, mas o que quero destacar é justamente o caráter moral e religioso da cultura sertaneja em um sentido maior. E isso, acredito, significa que a estética e o modo de vida local sejam infundidos numa moralidade particular no sentido de que não é necessário ser um penitente para sustentar 0 valor dessas práticas sociais de fundo religioso.

D esse modo, entendo que a mendicância não é apenas parte da penitência, mas, na verdade, um aspecto central do cenário cultural do Juazeiro do Norte. A mendicância, de fato, como Steil (1996) observa, tem um lugar e papel no cenário de peregrinações no Brasil. Andando pelas ruas estreitas de Juazeiro do Norte, muito facilmente encontramos pedintes, sejam eles penitentes ou não. D e fato, às vezes, a caracterização de um pedinte comum e de um penitente torna-se uma tarefa 
bastante difícil. Ao mesmo tempo em que não se pode negar que a pobreza local de raízes sociais e econômicas, além de ser bastante comum e forte, é certamente condutora da prática da mendicância, observa-se que o modo como essa pobreza é entendida pode transformar esse estado num modo moral de viver, ou seja, tratando-se mais de um tipo de transcendência material do que um estado de privação material pura e simplesmente.

Como Steil (1996) bem analisa, a esmola é um ato religioso. Significativa em si mesma, a esmola estabelece um laço, entre o doador e aquele que recebe, que de alguma forma é associado a Jesus. 0 autor também observa que, como a doação/ recebimento de esmolas situa-se num sistema de valores e significados religiosos, o milieu social que a origina é relegado a um status periférico para aqueles que tomam parte de tal sistema moral-religioso. Certamente não se questiona que a prática da esmola, principalmente o discurso ideológico que a acompanha, sirva como meio de manipular e esconder as relações de dominação e exploração. No entanto, acho bastante duvidoso que a caridade possa ser reduzida a tal uso ideológico. $\mathrm{Ou}$, pelo menos, acho extremamente insatisfatória a ex plicação sociológica para o fenômeno. Isto porque tamanha crítica à filantropia e à caridade não explica o porquê da promoção dos interesses de classe assumir a forma da dádiva (Silber, 1998, p. 140). Concordando com Silber, entendo que filantropia e caridade podem ser compreendidas além do contrato e da troca e a questão da ideologia envolvida nesse fenômeno não deve ser reduzida à dominação e à exploração. Meu argumento é que talvez possamos encontrar no nível da moral, um pouco à maneira de Mauss, caminhos mais interessantes para entender como fabricamos a sociedade. E para isso é necessário romper com explicações estruturais e racionalistas, e procurar, no nível da moralidade, isto é, como as pessoas se relacionam umas com as outras, os mecanismos da produção da sociabilidade (Overing, 1992, 1999). 
Nesse sentido, reconheço então que imagens de sofrimento e o lugar que os pobres ocupam na sociedade têm significados diversos de acordo com os diferentes contextos culturais, e que conceitos religiosos tais como caridade e misericórdia trazem consigo uma imagem ideal da sociedade, uma utopia. Não se trata aqui de simplesmente argumentar contra um caráter opressor e conservador com um supostamente "revolucionário" presente no sistema moral e de práticas da caridade, mesmo porque essa oposição parece não ter o potencial analítico e explicativo suposto. ${ }^{9}$ Mas, ao contrário, desejo apontar para a importância de sentimentos morais, mais do que motivação política ou econômica, na criação de uma sociabilidade baseada na fraternidade e que também se realiza através de uma espera messiânica. ${ }^{10}$ Estou, em outras palavras, chamando atenção para a dimensão moral na produção da sociabilidade. Como os indivíduos produzem diferentes formas de sociabilidade, é a questão maior em que se insere a minha preocupação com os Ave de Jesus e a sua espera messiânica.

É importante ainda fazer um contraste entre a mendicância e a caridade que acontece no Juazeiro e aquela praticada em grandes centros urbanos ou no que poderíamos chamar de um contexto "moderno" e secularizado. Ao contrário dos habitantes das grandes cidades modernas, os romeiros e penitentes do Juazeiro do Norte entendem a esmola mais como uma questão religiosa do que como uma expressão de consciência política e social. Como G odelier observa:

Pois a sociedade laicizou-se e a caridade, se está de volta, não se apresenta mais como virtude teologal, gesto de um fiel, de um crente. Ela é vivida pela maioria, crente e não-crentes, como um gesto de solidariedade entre humanos. Ela, que tinha recuado na medida em que havia um pouco menos de excluídos e um pouco mais de justiça social, retorna e volta a ser necessária quando, de novo, existem cada vez mais excluídos e o Estado já 
Revista de Antropologia, São Paulo, USP, 2003, v. 46 № 1.

não é capaz de fazer com que haja menos injustiça, menos solidões abandonadas. (1999, p. 10)

D e fato, no caso das campanhas de caridade no contexto moderno, as pessoas não dão esmolas, mas fazem doações financeiras e oferecem serviços e apoio afetivo como uma questão de justiça social. Apesar de em ambos os casos a mendicância ser entendida como um sofrimento, a experiência desse sofrimento ganha diferentes nuanças. O s sentimentos relacionados à mendicância, como a humilhação, estão provavelmente presentes nos dois contextos, entretanto os significados e valores morais atribuídos a esses sentimentos certamente são diversos. Portanto, como a mendicância é experimentada e a humilhação é sentida, leva a uma prática social certamente diversa. Caridade e filantropia, conforme eu as entendo, sugerem uma imagem ideal da sociedade e nos dizem sobre o lugar que os pobres nela ocupam. Mais importante: a caridade e a filantropia relevam a questão da distinção entre os merecedores e os "não-merecedores", entre os necessitados, os indigentes e os doentes, e também da acomodação entre o voluntarismo privado e as ações governamentais (Critchlow e Parker, 1998, p. 1). Por outro lado, caridade se diferencia da filantropia e das doações financeiras em geral realizadas no contexto moderno. A caridade tem sua origem e significação numa tradição religiosa, o que nos leva a um domínio de valores morais distinto daquele próprio de um espaço secularizado e informado pela razão moderna.

Argumento ainda que, para se entender a sociabilidade produzida pelos Ave de Jesus com sua alta valorização do sofrimento, pobreza e generosidade, temos de levar em conta o senso de moralidade desses indivíduos pela simples razão de que é a moralidade o modo pelo qual os Ave de Jesus se relacionam uns com os outros, ou seja, como constroem suas relações. ${ }^{11}$ Neste artigo, preocupo-me em compreender como as 
imagens do cristianismo primitivo e da Paixão fornecem os sentimentos morais associados à pobreza eà fraternidade, através dos quais esse grupo estrutura seu modo de vida.

E, ainda, demonstro como a espera messiânica dos Ave de Jesus se realiza através de imagens de caridade e compaixão em oposição aos interesses individuais e à troca orientada para o lucro. Penso oferecer uma visão em que outras dimensões que escapam à razão instrumental, por exemplo, o afetivo, o desejo e o sonho, permitem-nos reconhecer que conceitos como caridade, sofrimento e amor podem fazer parte de uma prática social e que não integram apenas um mecanismo ideológico escamoteador da realidade ou são passíveis de serem reduzidos a uma estrutura cognitiva inconsciente (reciprocidade/ troca). Em outras palavras, meu objetivo é demonstrar como essas categorias não são redutíveis a uma realidade puramente simbólica ou ideológica, mas constituem um modo de viver.

Pode-se perfeitamente chamar atenção para 0 fato de 0 afetivo, 0 desejo e o sonho não serem dimensões que escapam à razão - a obra de Malinowski é um "bom" exemplo para tal argumento. No entanto, o reconhecimento de uma razão pragmática no sonho, nos desejos, enfim no afetivo, não esclarece, na obra desse autor, seu conteúdo e lógica interna. Tal instrumental teórico apenas tornou o exótico familiar através de sua redução à lógica ocidental. Há ainda que lembrar aqui a crítica de Leach e Sahlins à formulação teórica de Malinowski. Este último autor, no entender daqueles, apresenta certa compulsão para dissolver costumes exóticos em noções utilitárias (Sahlins,1976, p. 75). ${ }^{12}$

Prefiro seguir com Malinowski quanto ao seu insight sobre "comunicação empática", em que salienta a função social da linguagem (produção de laços através de sentimentos) ao lado da função cognitiva e simbólica (imposição e comunicação de significados). Nas palavras de Malinowski, 
Revista de Antropologia, São Paulo, USP, 2003, v. 46 № 1.

words are used rather to fulfil a social function (...) this is their principal aim but they are neither the result of intellectual reflection nor do they necessarily arouse reflection in the listener (...) each sentence is an act serving a direct aim of binding hearer and speaker by a tie of social sentiment or other. (1923, p. 315)

Aqui 0 autor está próximo de Durkheim quanto à idéia de que as organizações sociais têm uma fundação emocional ou afetiva. Nesse sentido é relevante a importância dos rituais para a promoção de tais sentimentos. Meu argumento não segue o utilitarismo dos cânones do pensamento antropológico e sociológico, mas não posso deixar de reconhecer nesses autores uma trilha possível para se pensar a participação de sentimentos na fundação do social.

E, de fato, a emoção e os sentimentos têm um importante destaque em um cenário em que o sofrimento físico é a forma mais comum de expressão da religiosidade local. De modo que, antes de me deter sobre a questão específica da dádiva, devo explorar a relação entre sentimentos morais e modo de vida entre os Ave de Jesus. No início deste artigo, argumento sobre como a Bíblia fornece um modelo de sociabilidade para muitos sertanejos. Nas próximas linhas me esforçarei para demonstrar como esse grupo utiliza-se de imagens bíblicas na geração de sentimentos morais que fundam seu modo de vida. $\mathrm{O}$ u seja, como ao gerar sentimentos morais ele fabrica as relações (compartilhamento, solidariedade, hospitalidade etc.).

Juazeiro recebe aqueles que vão para chorar, consolar-se, compadecer-se e ser misericordiosos. É a manifestação desses sentimentos morais, a compaixão e a misericórdia, que é tomada pelos romeiros como evidência da natureza sagrada do Juazeiro. Nas palavras dos próprios romeiros, "D eus fez, aqui (Juazeiro), a sua morada". 0 espaço ocupado pelo sofrimento e compaixão é marcante no cotidiano da cidade do 
Juazeiro. Seja na aridez da geografia vizinha a Juazeiro, seja na presença acentuada de mendicantes, beatos e romeiros, das velas acesas, das promessas cumpridas e lembradas através dos causos contados durante 0 ano. Ao chegarem a Juazeiro, os romeiros e demais visitantes transformam-se em espectadores e testemunhas do sofrimento de outros penitentes. Uma vez em Juazeiro do Norte, veremos romeiros pobres, que mal tiveram o que comer na longa jornada, dar esmolas a penitentes e mendigos comuns. Veremos comunidades de penitentes oferecerem uma refeição, uma rede para se passar a noite àqueles que não têm condições de pagar por tais confortos. É, assim, que uma rede de fraternidade, compaixão e compadecimento parece se realizar através de cada ato de gentileza e hospitalidade nesse local (Campos, 2001).

A imagem bíblica mais saliente no cenário religioso de Juazeiro é a Paixão. A performance do sofrimento enquanto mímesis da crucificação pode ser assistida nos quatro cantos de Juazeiro através da penitência, das vestimentas e sofrimento social que penitentes, romeiros, pedintes, isto é, que a comunidade formada pelos devotos de Padrinho Cícero representa. A mimese é de tal forma evidente que podemos dizer que os corpos dos penitentes tornam-se uma narrativa bíblica, a narrativa da paixão. A importância da performance e da ritualização de imagens bíblicas parece-me um bom caminho para entendermos a participação dos sentimentos morais ligados a essas imagens no modo de viver dos Ave de Jesus. A importância da ritualização das imagens bíblicas também é evidente na fala de mestre José Ave de Jesus, líder fundador da comunidade: "Esse globo terrestre só tem movimento com a força e poder da divindade. Não é dizer. É ser e representar O Que É".

A principal questão está em como os eventos bíblicos e imagens de sofrimento influenciam 0 modo de vida do grupo. $\mathrm{O}$ u seja, qual é 0 papel social das emoções e suas relações com o código moral desses penitentes? Como eles experimentam as imagens religiosas? 
Revista de Antropologia, São Paulo, USP, 2003, v. 46 № 1.

"Nós somos os sofridos", disse-me uma das pessoas mais doces que eu jamais encontrei em minha vida, Maria Ave de Jesus. Comadre Valdenice é uma entre outras Marias Ave de Jesus. ${ }^{13}$ Ela já não caminha mais. Sofreu um acidente alguns anos atrás, enquanto fazia as tarefas domésticas, que lhe resultou na fratura do osso da pélvis. Os Ave de Jesus não se utilizam dos serviços médicos oficiais, e, assim, comadre Valdenice passou sofrimento e dor causados pela fratura e inflamação decorrente utilizando apenas ervas medicinais. Tudo isso sem queixas ou descontentamento e com a firme convicção de que se deve viver conforme as normas e conhecimentos tradicionais e rejeitar tudo aquilo que venha do progresso, como a medicina oficial.

Se alguém pergunta-lhe "como vai comadre?". Ela responde de imediato: "Eu vou muito bem, minha filha (meu filho), graças a Deus". Não se ouvirá queixas. Comadre Valdenice passa as tardes sentada à janela, conversando e dando conselhos a irmãos da comunidade Ave de Jesus, vizinhos e estranhos. É só na hora do A ngelus que seu marido a carrega em seus braços para o quarto; quando, então, ela fará as rezas antes de dormir como todos do grupo.

Os Ave de Jesus dizem viver "divididos" do mundo. Chamou-me atenção o uso de sinais e imagens de sofrimento, que eles fazem para marcar a separação que dizem ter do mundo. Não apenas do uso das imagens, mas também o cuidado estético envolvido nessas atividades simbólicas chama atenção. 0 nome, as cores e o corpo são freqüentemente usados e manipulados para comunicar a separação do mundo. Mais que isso, e, talvez, mais importante, é que os nomes, as cores de suas vestimentas (azul e branco, as cores de Maria) e o corpo não apenas marcam fronteiras com 0 mundo exterior e afirmam suas identidades sociais, mas, principalmente, expressam emoções de conteúdo altamente moral, como o pesar, a misericórdia e a compaixão. Aqui a relação com o renunciante em D umont (2000) é possível. Essa relação estaria 
na ambigüidade da relação do renunciante (indivíduo fora do mundo) com a sociedade que nega e da qual se afasta (mundo mundano). Afinal o renunciante depende da benevolência da sociedade mundana (fundada na troca) para sobrevivência. Ele também não age no mundo para transformá-lo (D umont, 2000, p. 38). Por outro lado, ao performarem a imagem da Paixão, os Ave de Jesus são capazes de provocar a benevolência ou a ação mitigatória daqueles que vivem no mundo, e acreditam estar assim criando a possibilidade de um outro modo de vida. A transformação moral dos indivíduos, dito de outro modo, tornandose os indivíduos mais solidários, ter-se-ia a possibilidade de um outro modo de vida, de uma outra sociabilidade. Vejamos adiante como isso se realiza.

A Bíblia, os causos, os benditos, além de serem gêneros narrativos de forma e conteúdo estéticos, funcionam como modelos de conduta. ${ }^{14}$ A través da Bíblia os Ave de Jesus aprendem a ser caridosos, misericordiosos etc. As imagens bíblicas associadas a tais emoções são constantemente produzidas e reproduzidas através dos causos, benditos e da prática da mendicância.

Os rituais são certamente o meio pelo qual exercem práticas de subjetivação (modos de ser caridoso, piedoso, misericordioso). Além de saírem em romaria para a igreja Nossa Senhora das Dores aos domingos, quando carregam consigo bandeirinhas nas quais se vêem as iniciais PPP para "pilidrino, pedinte e pidão", ${ }_{15}^{15}$ os Ave de Jesus saem diariamente para a mendicância. Esse ato é entendido como uma missão religiosa, um modo de levar a palavra de Jesus aos pecadores e é revestido dos mesmos cuidados que as práticas ritualísticas. Tal qual num ritual, na mendicância são observados cuidados estéticos, e, curiosamente, quando mendigam, os integrantes do grupo quase não falam. Costumam apenas dizer "Jesus seja louvado" e aqueles que oferecem a esmola dizem: "Que as dores de Nossa Senhora para sempre sejam lembradas". 
O cuidado estético com a roupa, a linguagem, o tipo de material dos utensilios domésticos e daqueles em que guardam as esmolas está diretamente relacionado à produção de sinais que evocam imagens bíblicas. Imagens associadas a caridade, misericórdia e compartilhamento. Ao performarem o sofrimento, os Ave de Jesus esperam despertar uma ação mitigatória ou compaixão, através de um ato de solidariedade.

A performance da dor, do sofrimento físico, torna o corpo desses penitentes uma espécie de narrativa humanitária. 0 corpo não é só 0 locus da dor, mas o elo entre os que sofrem e os que ajudam (Laqueur, 1995). Ele torna-se assim objeto da mercê, da misericórdia cristãs. Como observa 0 autor:

A exortação de Cristo a vestir, alimentar e abrigar os necessitados é interpretada, no Evangelho, no sentido de fazer o mesmo a Seu corpo: "Em verdade vos digo que, sempre que fizeste a um destes meus pequeninos irmãos, a mim o fizeste" (Mateus, 25: 40). 0 corpo universal do Deus que subiu aos céus intervém, aqui, entre sofredor e aqueles que praticam atos de misericórdia. (idem, 240)

\section{Caridade, salvação das almas e sociabilidade}

Caridade é muito mais que esmola, é mais do que simplesmente dar aos pobres. É definida no Cruden's Complete Concordance to the Bible como amor e benevolência. Nesse sentido, caridade implica atitudes e disposições psicológicas, implica ser generoso, benevolente, amoroso. Disso, entendo que caridade implica um modo de ser no mundo. E é certamente um modo de ser que os Ave de Jesus querem comunicar quando saem para a mendicância, com suas roupas em azul e branco, cabelos longos, sandálias de couro, cajados de madeira e rosário no pescoço. 
E quando dizem que o lugar onde vivem, Juazeiro do Norte, é a terra da misericórdia, certamente falam de um modo de viver e de se relacionar com 0 outro que acreditam existir por lá. Como já observei anteriormente, Juazeiro do Norte está localizada numa área seca, infligida periodicamente por longos períodos de estiagem e assim torna-se palco de sofrimento. Retirantes e penitentes juntos clamam por compaixão e misericórdia. Não importa se o sofrimento é socialmente infligido, ou voluntariamente auto-infligido como penitência, todo ele entra numa categoria: o Amor de D eus. Entendo assim que solidariedade (compartilhar alimentos, hospitalidade, esmola etc.) compõe o quadro ou a imagem do que 0 amor significa para a gente do sertão. ${ }^{16}$

Apesar de não ver os grupos de penitentes desse local como um movimento social, ou seja, como indivíduos engajados na transformação da sociedade, isso não significa que eles não nutram uma imagem ideal da sociedade. Nas próximas linhas argumentarei que através do amor cristão - a caridade -, das idéias de solidariedade e sofrimento, os Ave de Jesus forjam o modelo de sociabilidade.

Eles não aceitam dinheiro como esmola e nem comercializam os produtos de suas hortas. Portanto, nessa comunidade não há circulação de dinheiro. Se precisarem eventualmente de algum utensílio ou produto que não dispõem, em geral, trocam ou se utilizam estrategicamente da doação de parentes não convertidos. A pesar desse viés, a reciprocidade (dádiva) não é definida por relações de parentesco (filiação e aliança). Com quem se compartilha, "recíproca", e a quem se presenteia ligamse, no entanto, a um outro tipo de parentesco, um parentesco sagrado, a comunidade de irmãos, que se cria no próprio ato de doar/ receber motivado por um sentimento moral, o amor cristão e não por uma ancestralidade, uma aliança política ou econômica.

Por outro lado, há uma circulação regular de utensílios e alimentos que forma um sistema de troca baseado em princípios de mutualismo e 
comunhão. D ividir e compartilhar são a tônica da solidariedade do grupo. Se acaso alguém é obrigado a retribuir, não faz parte das preocupações dos Ave de Jesus, mas certamente dividir e compartilhar com aqueles que precisam, sim. D esse modo, a dádiva e a comunhão são as obrigações morais explicitadas. Como uma Ave de Jesus me disse: "D evese fazer o bem sem escolher a quem".

Alguém poderia dizer, por outro lado, que uma vez que todos são obrigados a dar, facilmente conclui-se que, numa situação em que todos são doadores, certamente existe reciprocidade. Ora, está fora de questionamento que os Ave de Jesus "retribuem" e "trocam" alimentos e utensílios tanto dentro como fora do grupo. A sobrevivência dele seria extremamente difícil sem a "troca". Meu argumento não se traduz numa negação ingênua e simplista da existência, entre o grupo, da troca regida pela razão instrumental. Meu argumento é de que o social é mais que isso. A razão instrumental e o cálculo são necessários à sobrevivência de qualquer grupo social, mas para que esta mesma possa se realizar eficazmente outros elementos são necessários (G odelier, 1999). A oposição entre razão e emoção é uma tradição de pensamento longamente debatida e de longe já vencida nas Ciências Sociais. A questão do que constitui 0 modo de vida dos Ave de Jesus reside nas bases e motivacooes da "troca" e da reciprocidade. Eu diria que a questão, na verdade, está no que se deve entender por reciprocidade.

Reciprocidade, tradicionalmente e de modo geral, nas Ciências Sociais, surge sob o signo da troca e do cálculo mais do que da dádiva e do compartilhar, sendo essas duas dimensões mais entendidas como ideológicas e escamoteadoras da realidade subjacente, racional e interesseira (Elster, 1994). Alguns autores como Elster (idem) e Silber (1998) chamam atenção para o fato de que esse tipo de postura teórica nega, no final das contas, a existência do altruísmo, da generosidade e de valores morais não individualistas. Os Ave de Jesus, por sua vez, definem-se e 
monitoram suas atividades por meio de uma moralidade fundada na solidariedade e fraternidade. A dádiva é, na verdade, a prática social através da qual eles dão existência a si próprios enquanto "Ave de Jesus": um grupo de penitentes que vive pelo Amor de D eus. A "reciprocidade" existe entre os Ave de Jesus, mas esta se funda nos valores comunais em oposição a uma moralidade fundada em princípios individualistas. Isso faz toda a diferença para a compreensão da reciprocidade que não seja regida pelo cálculo. Entendo que a diferença está mais nas intenções morais da dádiva que exatamente na obrigação da reciprocidade. Como Godelier (1999) bem observa, a característica marcante da dádiva não está na ausência da obrigação, mas na ausência do cálculo.

A troca de mercadorias em si mesma não é um problema para os Ave de Jesus. 0 problema está na verdade da forma que essa troca adquire através das motivạões e interesses. Nessa questão eles estão bastante próximos das idéias de Aristóteles quanto à da troca baseada no lucro ser contra a ordem natural, a qual, na visão dos Ave de Jesus, foi estabelecida por $D$ eus. D e fato, toda a vida econômica dessa comunidade gira em torno dos valores e laços comunais. A sobrevivência dos membros do grupo depende de atividades produtivas estruturadas em valores e laços comunais, tais como a horta comunal, a mendicância associada à proibição da circulação e do uso de dinheiro dentro do grupo. Ao mesmo tempo a circulação dos produtos se faz através do compartilhamento de alimentos e utensílios provenientes tanto da mendicância como da horta comunal.

A reciprocidade foi definida por Mauss pela tríade "dar, receber e retribuir". D epois desse autor, houve uma tendência nas Ciências Sociais a se enfatizar a obrigatoriedade em se retribuir. 0 que, eu suspeito, tenha sido a razão de uma aproximação com a troca mercantil, enquanto "analogia" para a dádiva, em que o cálculo é elemento imprescindível. Esclareço que não estou simplesmente opondo razão instrumental à 
razão simbólica (Sahlins, 1976), pois se assim o fosse não caberia a crítica a Lévi-Strauss. A razão simbólica fundada na reciprocidade nada mais diz que temos a reciprocidade/ troca, de natureza cognitiva e universal, da qual não podemos escapar, como fundamento de nossa existência social e cultural. Meu argumento teórico não se situa em uma estrutura social ou mental exterior ao fenômeno. Nesse sentido, tomo um Godelier mais recente, em específico, no livro 0 enigma do dom, que salienta a necessidade de voltarmos à tradição maussiana. $\mathrm{Ou}$ seja, de trabalharmos no nível das motivaọ̃es onscientes e do imaginário dos nativos e, portanto, justifica-se a importância da moral para se compreender a dádiva. É no sentido de opor a reciprocidade regida por ganhos materiais, sociais ou simbólicos, que eu sugiro a definição da reciprocidade em termos da ausência do cálculo. Sem dúvida, isso nos leva a um outro problema que é da Moral. No caso dos Ave de Jesus, entendo que sua moralidade define-se não como aquela em que o "outro" é tomado como meio na avaliação instrumental para se atingir um fim, mas como organização do grupo que tem por objetivo a salvação do "outro" dos pecados do mundo. A salvação, ainda é preciso que se diga, passa pela transformação afetiva dos indivíduos. D e egoístas e prepotentes a generosos, caridosos e humildes.

A principal atividade do grupo é chamada por eles de a Roça da Mãe de Deus. Viver na penitência é, acima de tudo, viver sob o sinal da misericórdia; é viver, como eles dizem, "pelas mãos de D eus". Todo e qualquer alimento da dieta dos Ave de Jesus deve vir do amor e da misericórdia. Qualquer colheita da Roça da Mãe de D eus é uma colheita do Amor Cristão. Como o próprio nome dado à mendicância já anuncia, a imagem que dá suporte ao sistema de práticas e valores é a imagem de Maria, que, como mãe, amparou e consolou seu filho em terrivel dor e sofrimento injustos. E Maria, como mãe de todos os sofridos, é aquela que os consola. 
Inspirados por essa imagem de compadecimento, os Ave de Jesus também consolam aqueles que têm fome e batem às portas pedindo pelo A mor de D eus. A mendicância é central à existência dos Ave de Jesus. Sem tal prática, eles não existiriam. De fato, o grupo mendiga diariamente independentemente da quantidade de alimentos em estoque. Eles fazem assim não porque seja a esmola 0 principal objetivo, mas sim mover o coração dos indivíduos a fim de nutrir nele a generosidade e a fraternidade. A mendicância não é um ato de sobrevivência pura e simples, mas uma missão religiosa e moral. 0 líder dos Ave de Jesus também me disse:

Exatamente... Nós pedimos para lembrar os nossos irmãos (sic) as palavras de D eus. Não devemos glorificar o Senhor com qualquer coisa. Não podemos dizer o que queremos... o que tá faltando em casa. Não, não podemos dizer o que precisamos. Não. Não dizemos o que precisamos. D eus é que manda no coração. Eu disse a palavra de Deus... Então o que ele põe no seu coração é o que você me dá e o que eu recebo.

Alguém poderia lembrar que a esmola está fortemente relacionada com a questão da salvação no cristianismo e, talvez, a reciprocidade enquanto troca e cálculo seja aí evidenciada. Entretanto, argumento que caridade vai além da interpretação usual, qual seja: "dar aos pobres com a intenção de satisfazer a D eus". Vejo nessa interpretação uma dificuldade que apresento a seguir. A troca, nesse caso, é posta na pós-morte e assim temos mais uma soteriologia da reciprocidade que propriamente uma sociologia (Parry, 1986). Nesse sentido, a caridade torna-se de pouco interesse sociológico, e, talvez, seja esta a razão da caridade de cunho religioso ter ocupado pouco espaço nas Ciências Sociais. Entendo que mais interessante do ponto de vista antropológico é se perguntar como 
Revista de Antropologia, São Paulo, USP, 2003, v. 46 № 1.

tal soteriologia está relacionada à imagem de uma sociedade ideal. E assim, quem sabe, encontrar uma sociologia da solidariedade.

Mas então voltemos para os Ave de Jesus. Mestre O lício Ave de Jesus - mestre da arte dos benditos na comunidade - contou-me um "causo":17

Tinha um homem muito rico que pensava que era o $\mathrm{D}$ eus da cidade onde morava... e um irmão que batia na sua porta todos os dias. Um dia, era meio-dia, quando o homem rico tava descansando, disseram a ele que em três dias o homem mais rico da cidade ia morrer (sic). Então, ele caiu doente, e o doutor foi chamado para dar uma olhada nele. No dia seguinte, a mesma visão apareceu novamente e disse: "O homem mais rico na cidade vai morrer (sic) amanhã”. Aí o homem rico ficou mais doente. No dia seguinte, na mesma hora, dois homens que passavam por sua porta disseram: "Ei, o senhor sabe quem acabou de morrer debaixo da ponte? Aquele mendigo (sic) que costumava bater na sua porta" . Então, o homem grande disse: "Que conversa é essa? Q uem tá falando?". Os dois homens disseram: "Sim senhor, aquele esmolé (sic) que passava aqui todos os dias acabou de morrer". "João, vai na casa do padre, diga a ele para chamar as freiras e venha para carregar o meu corpo!", o homem rico disse. Aí, ele mesmo pegou uma toalha e pegou o corpo do mendigo com todo o cuidado, e trouxe para a sua casa. Aí ele mandou que fosse feito um caixão para um homem rico de verdade. Então ele disse: "Esse é o homem mais rico da cidade. Eu pensei que era eu, mas estava enganado. 0 homem mais rico é este aqui".

Os Ave de Jesus corporificam seus valores morais através do sofrimento, da pobreza, da humildade e simplicidade em oposição a valores materiais. A imagem do Cristo como mendicante é incorporada de alguma maneira à noção de uma "comunidade de sofridos" . Assim, quan- 
do se é gentil e misericordioso com um pedinte desconhecido poder-seia estar ajudando ao próprio Cristo. Entretanto, o modo de vida dos Ave de Jesus, moldado pela penitência, não é "apenas" uma questão de salvação, mas é também algo que tem forte relação com uma imagem particular da sociedade. A idéia da caridade como uma barganha pela salvação é bastante rejeitada pelos Ave de Jesus. A idéia de se comprar um pedacinho do Céu através da caridade soa como pura blasfêmia a esses penitentes. Para melhor compreender essa questão é necessário entendermos como os Ave de Jesus estão organizados socialmente.

A pesar de não haver propriedade comum da terra, nessa comunidade, como aconteceu em outros movimentos messiânicos, ${ }^{18}$ a divisão da colheita da horta comunal, cuja terra está no nome de mestre José, ${ }^{19}$ segue o princípio da necessidade de cada família. Por outro lado, os "produtos" da mendicância são considerados individuais. Esse ponto precisa de maiores esclarecimentos. Q uando um Ave de Jesus traz coisas da mendicância, essas são coisas do "mundo de fora" produzidas pelo esforço individual - por definição esses produtos ou coisas são trazidos para 0 grupo pelo indivíduo. Uma vez que a moralidade da generosidade é importante para os Ave de Jesus, tal situação é crucial para o indivíduo. De acordo com os princípios e valores morais dos Ave de Jesus, ele, o indivíduo, deve ser generoso e misericordioso e, ao mesmo tempo, uma vez que os produtos da mendicância são individuais, cabe ao Ave de Jesus decidir o que fazer com eles. Essa é, portanto, uma situação crucial e altamente simbólica em relação à identidade de cada membro em particular dentro da comunidade Ave de Jesus. Como se comportará cada um deles? De fato, a força do carisma de cada um dos Ave de Jesus é certamente uma questão de quão sofredor, generoso e misericordioso cada um é. D esse modo, ser um verdadeiro penitente - um Ave de Jesus - vai muito mais além, isso do ponto de vista sociológico, do que simplesmente obedecer e seguir os D ez Mandamentos. Para se atingir tal 
Revista de Antropologia, São Paulo, USP, 2003, v. 46 № 1.

status - verdadeiro penitente - é preciso internalizar determinadas disposições psicológicas relacionadas à compaixão e caridade (Amor de D eus).

D e uma forma ou de outra, os produtos provenientes da mendicância circulam no grupo, juntamente com aqueles produzidos na roça comunal e na rede de relações sociais externas (vizinhos, parentela, amigos, estranhos), seguindo o princípio moral da mutualidade e generosidade. É bastante comum ver vizinhos dando alimentos e utensílios àqueles Ave de Jesus por quem têm apreço. É também comum ver romeiros oferecerem esmolas em forma de alimentos aos Ave de Jesus.

A trajetória que os alimentos fazem ganha diferentes contornos e pode tomar parte de diferentes "sistemas" de dádiva, caso os alimentos circulem dentro do grupo (compartilhar, comunhão) ou envolva estranhos (esmola). De qualquer modo, ambos os casos pertencem a um sistema mais abrangente que é 0 Amor de D eus. Os membros dos Aves de Jesus compartilham suas comidas com amigos e estranhos durante festividades e ocasionalmente no cotidiano. O ferecer hospedagem e alimento é parte de sua hospitalidade e obrigação na celebração do calendário religioso quando acontecem as festividades. D e fato, nunca estive em campo sem que eles me oferecessem refeições ou uma fruta para que eu pudesse comer no caminho de volta ao centro da cidade. Presentes e esmolas são entendidos sob o mesmo signo que é o A mor de D eus, tanto um como outro são dados por amor. Aquilo que é dado, acreditam os Ave de Jesus, jamais deve ser dado por interesses individuais ou por cálculo. Portanto, nem é a troca nem a reciprocidade - como definida no sentido tradicional, isto é, pela obrigação em retribuir - que funda e rege o modo de vida dos Ave de Jesus.

É interessante observar a importância que a comida tem na religiosidade popular. 0 "uso" de comida em rituais mais estudados é aquele das religiões afro-brasileiras, em que a comida toma a forma de sacrifício aos deuses (Motta, 1991). No Juazeiro, no contexto do catolicismo 
popular, a comida circula cotidianamente, mas também de forma ritualística, já que representa simbolicamente imagens bíblicas. Aqui, 0 contraste entre ritual e cotidiano é de pouca utilidade. Se no Xangô a comida é oferecida aos deuses e compartilhada pela comunidade de crentes, no Juazeiro, ela é oferecida ao homem. Certamente, há aí um caráter sacrifical ao D eus, mas há também um componente afetivo e moral que faz diferença em termos de sociabilidade. Nas religiões afro-brasileiras, a solidariedade ${ }^{20}$ gerada pelo compartilhamento da comida sacrifical parece ser interna, ou seja, voltada para o grupo. No catolicismo popular, exemplificado pelos Ave de Jesus, a solidariedade é tanto interna como externa. $\mathrm{O}$ alimento é compartilhado internamente entre os membros e com estranhos - ainda que cristãos, mas estranhos. Argumento que a comida que circula no catolicismo popular vem de D eus e é oferecida em seu nome. Na visão de romeiros e de penitentes, Juazeiro é sagrado, pois lá se pode presenciar a compaixão e a misericórdia. A interpretação local de que no Juazeiro encontra-se misericórdia passa pela prática de penitências e caridade, sinais do Amor de D eus e de Sua presença no lugar.

O papel da caridade na constituição das práticas sociais dos Ave de Jesus, no meu entender, pode ser interpretada nos mesmos termos teóricos que Parry (1986) e G odelier (1999) se utilizam para o hau. ${ }^{21} \mathrm{Ape}-$ sar da distância etnográfica entre o hau e a caridade, eles se aproximam num nível mais geral enquanto categorias nativas utilizadas para explicar sistemas de práticas sociais regidos pela reciprocidade. ${ }^{22} \mathrm{Na}$ noção de hau tem-se a idéia de que o doador está de alguma forma representado no presente. Nessa interpretação, é o hau que faz o presente (o objeto doado) retornar ao dono; portanto, pode-se dizer, é o hau que cria um sistema social baseado na reciprocidade. Nesse sentido, as categorias nativas se materializam em um sistema de práticas (Godelier, 1999). Parry (1986) e Godelier (1999) argumentam sobre a importância de 
entendermos os conceitos nativos como parte de práticas sociais e não apenas como uma explicação falsa ou enganosa do real. Neste sentido, não tomo caridade (Amor de D eus) como algo que esconde um jogo de interesses e de classe. Tal qual o hau, é a caridade que "cria" um modo de ser e de se relacionar com o outro e assim constitui uma sociabilidade particular. Certamente, a caridade engendra práticas diversas, mas é ela, assim como o hau, que faz a dádiva "circular". Se, entre os Maori, a sociabilidade é criada através do espírito da dádiva (ver G odelier, 1999; Parry, 1986; Mauss, 1990) - hau - , entre os Ave de Jesus é o próprio ato de doar, de presentear, de ser generoso que dá existência ao modo de vida deles e lhes confere status moral. Se em um é o espírito da coisa dada, no outro é 0 ato de dar, entendido como o Amor de D eus (caridade), que cria laços sociais. $O$ ato de dar torna estranhos irmãos e irmãs. É através da doação e do compartilhar que os Ave de Jesus nutrem as bases sociais de uma sociedade ideal estruturada em amor, hospitalidade, generosidade e fraternidade. Entendo que a vida econômica desse grupo (roça comunal e mendicância) é parte central da produção de sua sociabilidade. Disso não se conclui que eu esteja pondo no econômico qualquer determinismo social. Meu ponto é bem diverso e para isso recordo Godelier (1999) no livro 0 enigma do dom: sempre há elementos do domínio humano que não são governados pelo contrato. ${ }^{23}$ Elementos tais que, ao mesmo tempo, precedem a troca e nos quais a troca tem raízes e elementos que a caridade pode representar. A caridade certamente representa a fundação da vida social dos Ave de Jesus. Uma vez que as práticas sociais do grupo são uma crítica à sociabilidade da sociedade mais ampla, hegemônica, podemos dizer que eles, através de seu modo de vida, purificaram a vida social. Em outras palavras, eles elevaram a sociabilidade a um modo de vida. De fato, eles acreditam que, através da dádiva, da generosidade e da fraternidade, o egoísmo, a violência e 0 luxo podem ser suprimidos. A afetividade corporificada no ato da cari- 
dade torna plausível a Cidade de D eus, e essa utopia é assim vislumbrada e adquire realidade quando os Ave de Jesus saem em mendicância dramatizando a esperança.

\section{Notas}

10 desenvolvimento das idéias deste artigo deve à leitura cuidadosa e crítica de Joanna Overing, David Riches, Otávio Velho, Márnio Teixeira Pinto, Paulo Henrique Martins, Andrea Oliveira Castro e outros. A todos eles agradeço a valiosa contribuição.

2 O conceito de "cultura bíblica" em Otávio Velho (1995) tem levado a uma nova geração de etnografias dos movimentos messiânicos e milenaristas. Tais etnografias apresentam uma abordagem que difere da interpretação clássica do fenômeno messiânico enquanto movimento social, investigando-se seu caráter revolucionário, reformador ou conservador, e propõem sua compreensão como manifestação cultural.

3 Vale sempre a pena lembrar que Lévi-Strauss peca no sentido de que sua síntese teórica não nos fornece instrumental para dar conta de uma sociabilidade fundada em sentimentos morais. Ele peca do ponto de vista do que se quer discutir neste artigo; ou seja, a possibilidade de pensarmos outras maneiras, outros modos ou fundamentos da constituição do social. Entretanto a sua obra em termos descritivos, exemplificada no trecho acima, remete à sociabilidade e aos sentimentos associados.

4 Há que se perdoar $\mathrm{G}$ odbout pelos exageros pois não é o primeiro nem 0 último autor a cair nas armadilhas da retórica.

5 Idéias discutidas em comunicação pessoal com Adolfo O liveira.

6 Uma atenção às teorias nativas pode muitas vezes ser confundida com uma "mistificação pela teoria nativa”. Esse é um problema difícil na Antropologia, que se in- 
tensifica com as críticas epistemológicas e de conteúdo político trazidas pelo interpretativismo, ou por uma Antropologia pós-moderna. Entretanto, mesmo aqueles que não se identificam com tal paradigma têm reconhecido os limites do conhecimento antropológico e buscam uma ampliação deste conhecimento através da própria abertura para as filosofias nativas (Viveiros de Castro, 2002; O vering, 1985; G oldman, 2001). Meu caminho, no caso dos Ave de Jesus, é levar em conta as motivações conscientes, a moralidade do grupo e analisar como as categorias nativas se realizam ou operam em termos de práticas sociais. D e modo que não penso cair presa da crença nativa.

7 Penitência e mendicância têm uma antiga tradição no Sertão. Líderes religiosos como Padre Ibiapina, Antonio Conselheiro e o beato Zé Lourenço são bons exemplos dessa prática religiosa (Campos, 2001).

8 Ver Anderson (1970) sobre como a comunidade de Caldeirão foi capaz de enfrentar a grande seca de 1915 e ajudar os flagelados que chegavam a Juazeiro em completo desamparo por parte do Estado.

9 A oposição do caráter conservador e revolucionário dos movimentos messiânicos não é excludente em um mesmo movimento messiânico. Como bem argumenta Michel Lowy (1990), conservadorismo e progressismo podem vir juntos.

10 Muitos são os estudos, hoje clássicos, que explicam o messianismo através dos ganhos sociais, políticos e econômicos (ver Q ueiroz, 1965; Anderson, 1970; D ella Cava, 1970; Facó, 1991; e outros).

11 Para compreender a importância de uma etnografia da moralidade, ver Howell (1997).

12 Nas palavras de Sahlins, "Malinowski, this criticism implied, refuses to oncede to any opacity in the cultural system, let alone to understand its inhrent logic. W hole areas of culture thus escape a funcionalist ex plication, since they make no apparent pratical sense" (1976, p. 75); e mais à frente, ainda acrescenta: "Utilitarian functionalism is functional blindness to the content and internal relations of the cultural object. The 
content is appreciate only for its instrumental effect, and its internalconsistency is thus mystified as its external utility. Funcionalist ex planation is a kind of bargain made with the ethnographic reality in which content is exchanged for an 'understading' of it" (idem, p. 76).

13 Aqueles que pertencem ao grupo Ave de Jesus são "batizados na cruz" - em alusão à penitência - com os nomes Maria e José.

14 Este fato me leva à distinção entre regras de conduta e "modos de ser" feita por Foucault (1987). O modo pelo qual as pessoas aprendem a agir de acordo com regras e valores serviu a Foucault (p. 25) como uma importante distinção entre regras de conduta e modos de ser (subjetivação e práticas do self). Como o autor salienta, algumas sociedades enfatizam as instâncias de autoridade e poder que reforçam o código moral e as normas sociais, outras enfatizam as técnicas através das quais o sujeito aprimora o self e que possibilitam a transformação do modo de ser no mundo. Em outras palavras, algumas sociedades preocupam-se como forçar os indivíduos a seguir regras; outras, com o modo de ser dos indivíduos no mundo. Entendo que os Ave de Jesus, mais do que seguir os D ez Mandamentos, aprendem a ser piedosos, caridosos e sofredores.

15 Percebe-se aqui que o humor não está ausente numa situação de tão forte ascetismo e austeridade.

16 Quando me refiro à gente do sertão, estou me referindo àqueles sertanejos que, de uma forma ou de outra, estão imersos numa moralidade católica.

17 Um "causo", dito também passagem, é um tipo de narrativa de tradição oral bastante presente na cultura rural nordestina. Um "causo" é contado como quem conta uma estória, uma lenda, mas que, por outro lado, intenciona relatar fatos supostamente ocorridos e, portanto, tem valor de verdade.

18 Caldeirão e o movimento messiânico de Santa Brígida liderado pelo velho Pedro são alguns exemplos - conforme Anderson (1970) e D ella Cava (1970). 
19 Apesar de mestre José ter me dito que o terreno da horta comunal pertence a um vizinho, que ao sair da área pediu a ele que tomasse conta, sua mulher, comadre Regina, informou-me que o terreno foi comprado por mestre José. A versão de comadre Regina parece ser mais plausível, pois é coerente com outras informações obtidas fora do grupo de que mestre José teria sido um pequeno comerciante no Juazeiro e que teria vendido o que tinha para fundar uma comunidade de penitentes. Ao mesmo tempo, comadre Regina sempre foi mais receptiva à minha presença no grupo, confiando em mim e contando-me eventos que mestre José, por ser mais cauteloso, sempre guardou reserva das informações que pudessem ser interpretadas de forma negativa contra sua pessoa. Além disso, mestre José exerce o papel de negociador de significados entre o mundo de fora e sua comunidade, o que indica que ele é consciente do lugar que ocupa na sociedade e dos conflitos entre os dois sistemas de interpretação, sendo assim mais cauteloso (Campos, 2001).

20 Solidariedade é aqui pensada como atos de solidariedade, de ajuda, de compartilhamento. Não tem qualquer referência à solidariedade no sentido funcional. 0 que não quer dizer que não se possa estabelecer relação entre práticas de compartilhamento da comida e reforço de laços comunais.

21 Faz-se necessário esclarecer a comparação entre o grupo Maori e o nordestino. A alusão aos Maori é apenas a título ilustrativo. Tanto é que me atenho mais às diferenças. A comparação no sentido de apontar as semelhanças é sem dúvida mais interessante e profícua, mas é também, sem dúvida alguma, metodologicamente mais sofisticada e vai além de uma intenção meramente ilustrativa. Ao mesmo tempo gostaria de lembrar que o grande divisor entre sociedades complexas e sociedades tradicionais que se estabeleceu em nossa disciplina, a Antropologia, tem conseqüências perversas no sentido de inviabilizar o diálogo entre as produções entre esses dois campos de pesquisa. Um paradoxo, pois as grandes teorias clássicas, das quais bebemos até hoje, têm como base de reflexão as sociedades tradicionais.

22 D eve-se ter em mente aqui que a crítica às teorias da reciprocidade está em sua redução à "troca". D efendo ao longo deste texto uma outra definição para reciprocidade. Uma definição que leve em conta a moral. 
23 Godelier (1999) refere-se em especial àquilo que se guarda, como, por exemplo, as relíquias religiosas. Entretanto, na introdução de seu livro, ele chama atenção para o problema da filantropia como um dos domínios da vida social que não é regido pela troca. No meu caso, estou estendendo ao que não é negociável à caridade, pois esta não envolve cálculo ou negociação.

\section{Referências bibliográficas}

ANDERSON, J. C.

1970 The Caldeirão M ovement: a case study in Brazilian M essianism 1926-1938. Tese de D outoramento. The G eorge Washington University, mimeo.

BARROS, L. O.

1988 A terra da Mãe de D eus. Rio de Janeiro, Francisco Alves.

BAÊTA NEVES, L.F.

1997 V ieira e a imaginação social jesuítica. Rio de Janeiro, Topbooks.

BLOCH, E.

1995

The Principal of H ope. Cambridge, Mass., The MIT Press, v. 2.

BLOCH, M.

1989 Money and the morality of ex change. Cambridge, Cambridge University.

1982 \& PARRY, J. D eath and Regeneration of L ife. Cambridge, Cambridge University.

CAMPOS, R. B. C.

2001 W hen Sadness is Beautiful: a study of the place of rationality and emotions within the social life of the A ve de Jesus. Tese de D outoramento. D epartment of Social Anthropology, St. Andrews University-UK, datilo.

CONSORTE, J. G. \& NEGRÃO, L. N.

1980 O messianismo no Brasil contemporâneo. Religião e Sociedade Brasileira, v. 1, FFLCH/ USP-CER. 
CRITCHLOW, D. \& PARKES, C. H.

1998 W ith Us A lways. London, Rowmand Littlefield Publishing.

CRUDEN, A.

s./ d. Cruden's Complete Concordance to the Bible. Cambridge, Lutterworth.

CUNHA, E. da.

1979 Os sertões. São Paulo, Abril Cultural.

DELUMEAU, J.

1997 Mil anos de felicidade, uma história do paraíso. São Paulo, Companhia das Letras.

DELLA CAVA, R.

1970 Mirade at Joaseiro. New York/ London, Columbia University.

DUMONT, L.

$2000 \quad 0$ individualismo: uma perspectiva antropológica da ideologia moderna. Rio de Janeiro, Rocco.

ELSTER, J.

1994 Peças e engrenagens das Ciências Sociais. Rio de Janeiro, Relume-D umará.

FABIAN, J.

1998 Moments of Freedom: A nthropology and Popular Culture. Charlottesville/ London, University of Virginia.

FACÓ, R.

1991 Cangaoiros e fanáticos. Rio de Janeiro, Bertrand.

GODELIER, M.

1999 The enigma of the gitt. Chicago, The University of Chicago.

20010 enigma do dom. Rio de Janeiro, Civilização Brasileira.

GOLDMAN, M.

2001 D o ponto de vista não-nativo: sobre a incompreensão antropológica. Comunicação pessoal, XXV Encontro Anual da ANPOCS. 
HOWELL, S.

1997

The E thnography of M oralities. London/ New York, Routledge.

LANNA, M. P. D.

1995 A dívida divina. Campinas, Unicamp.

LAQUEUR, T.

1995

Corpos, detalhes e a narrativa humanitária. In: HUNT, L. (ed.) A nova história cultural. São Paulo, Martins Fontes.

LOWY, M.

1990 Romantismo e messianismo: ensaios sobre L uckács e Benjamin. São Paulo, Perspectiva/ Edusp.

MACINTYRE, A.

1981 A fter V irtue: A study in moral theory. London, Duckworth.

MALINOWSKI, B.

1923 The Problem of Meaning in Primitive Languages. In: OGDEN, C. K. \& RICHARDS, I. A. (eds). The Meaning of Meaning. London, Harcourt Brace \& Co.

MAUSS, M.

1990

The G ift. London, Routledge.

MOTTA, R.

1991

E djé Balé: alguns aspectos do sacrifício no X angô de Pernambuoo. Recife, tese para professor titular. D epartamento de Ciências Sociais, UFPE.

OVERING, J. (ed.)

1985

Reason and Morality. London, Tavistock.

1992

Wandering in the Market and the Forest: An Amazonian Theory of Production and Exchange. In: DILLEY, R. (ed.) Contesting Markets: analyses of Ideology, D iscourse and Practice. Edinburgh, Edinburgh University.

1999 Elogio do cotidiano: a confiança e arte da vida social em uma comunidade Amazônica. Mana, v. 5(1): 81-107. 
Revista de Antropologia, São Paulo, USP, 2003, v. 46 № 1.

PARRY, J.

1986

The Gift, the Indian gift and the "Indian gift". Man (n./ s.) 221, 453-73.

QUEIROZ, M. I. P.

1965

0 messianismo no Brasil e no mundo. São Paulo, D ominus/ Edusp.

1973

Os penitentes. In: Campesinato brasileiro. Petrópolis, Vozes, p. 171-76.

REDDY, W.

1997

Against Constructionism. Current A nthropology, v. 38 (3), Jun., The University of Chicago.

SAHLINS, M.

1976

Culture and Practical Reason. Chicago/ London, The University of Chicago.

SILBER, I.

1998

Modern philanthropy: reassessing the viability of a Maussian perspective. In: JAMES, W. \& ALLEN, N. (eds.) Marcel M auss, a C entenary Tribute. New York/ Oxford, Berghahn Books.

STEIL, C. A.

19960 sertão das romarias. Petrópolis, Vozes.

VELHO, 0.

1995 A besta-fera: recriação do mundo. Rio de Janeiro, Relume-D umará.

VIVEIROS DE CASTRO, E.

2002 O nativo relativo. Mana, v. 8(1): 113-48. 


\begin{abstract}
This article provides a discussion on how images of charity are related to an ideal image of society - a U topia. By going deeper into the relation between images of suffering, poverty and mendicancy I explore how a group of penitents "the Ave de Jesus" from Juazeiro Norte creates a sociality based on generosity, hospitality and sharing whereby they realise a messianic expectation. The major argument leads to a more general discussion of the bases of social life, the material on the Ave de Jesus serving to stress the significance of sociality based on charity and a whole complex organized around it that challenges some classical athropological theory on giftreciprocity.
\end{abstract}

KEY-WORD S: gift; moral sentiments; messianic expectation. 